\title{
Daily expenses of foreign tourists, length of stay and activities: evidence from Spain
}

\author{
ANTONIO GARCÍA-SÁNCHEZ \\ Department of Economics, Technical University of Cartagena, Calle Real, 3, 30201 \\ Cartagena, Spain.E-mail: a.garciasanchez@upct.es.
}

ESTER FERNÁNDEZ-RUBIO

Department of Economics, Technical University of Cartagena, Calle Real, 3, 30201

Cartagena, Spain. E-mail: e.fernandezrubio@gmail.com

\section{DOlORES Collado}

Department of Economics, Alicante University, Campus de San Vicente, 03080 Alicante, Spain.E-mail: collado@ua.es. (Corresponding author.)

\begin{abstract}
One of the most salient topics in tourism studies is the analysis of factors driving tourist expenditure decisions, given their impact on destinations and the consequences for marketing strategies. Tourist expenditure in a given destination is the result of considering both the length of stay and the daily expenditure. The objective of this research is to analyse daily tourist expenditure determinants using a survey of foreign tourists visiting one leading destination in Southern Europe: the Spanish Mediterranean coast. It focuses on two aspects: how the length of stay influences daily expenditure and how the different activities of tourists during their stay affect tourist expenditure. The research employs a dataset of nearly 184,000 observations covering 2004-2009 and includes tourist socio-economic characteristics and elements related to the trip. The results confirm that tourist expenditure is explained by a set of tourist-related social and economic factors and these factors shed light on the consequences of strategies to extend the length of stay of tourists. Finally, the effect on the daily expenditure of tourists' activities helps to determine the complementary supply (health, culture, gastronomy, etc) that must accompany mature sun-and-sand destinations.
\end{abstract}

Keywords: tourist expenditure; length of stay; tourist activities; tourist demand segments; Southern Spain

The authors would like to thank the Spanish Institute for Tourism Studies for providing the dataset for this research. The study is a result of research project $08736 / \mathrm{PHCS} / 08$ supported by the Programme for Scientific Generation of Fundación Seneca-Región de Murcia under II PCTRM 200710 and, also, it has been possible thanks to the support of the Ministry of Science and Innovation. Collado gratefully acknowledges financial support from the Spanish Ministry of Education and Science (ECO2011-29751). 
It is well known that tourism is one of the most important economic activities in Spain. Some 52.2 million tourists visited the country during 2009, which represents an $11.4 \%$ share of international tourist arrivals in Europe. These figures make Spain the third largest country in the ranking of the world's major tourism destinations in terms of international tourist arrivals, after the USA and France. Furthermore, Spain received US\$53.2 billion in 2009 that represents a $12.9 \%$ share of international tourism receipts in Europe (World Tourism Organization (WTO), 2010). Regarding international tourism receipts, Spain is the second largest country after the USA. According to the Tourism Satellite Account (TSA) from the Spanish National Statistical Institute, tourism represented $10 \%$ of the gross domestic product (GDP) and employed $11.5 \%$ of the working population in the national economy in 2009 (Spanish Institute for Tourism Studies (SITS), 2010).

At the same time, tourism has experienced a continued growth and diversification to become one of the largest economic sectors in Spain, but also in the rest of the world. In fact, from 1950 to 2009, international tourist arrivals worldwide grew from 25 to 880 million (WTO, 2010). The WTO (2010) estimated that the number of international people movements around the world will reach 1,600 million by 2020 . Consequently, the participation of the world tourism industry in the world's GDP will increase to $10.9 \%$ in 2014 (World Travel and Tourism Council, 2005). These figures reinforce the fact that investigating all tourism aspects is extremely important for all economic agents: government, companies and families.

Moreover, tourism appears as an economic activity capable of transferring revenue from the richest countries to the countries with lower development levels. In fact, the main issuing markets are countries with higher income levels. Destinations showing a major growth in the number of tourists received over the last decades have lower income per capita levels than those from issuing countries. In this sense, Lee and Chang (2008) point out that tourism development has a higher impact on GDP in non-OECD countries than in OECD countries.

Additionally, Zhao and Ritchie (2007) note that tourism analysis has now gained scientific status and that research interest in the academic community has also grown. This increase in research in the tourism field can be confirmed with the evolution of the number of research projects, published research articles or scientific journals dedicated to tourism analysis.

One of the main reasons for the increase in interest is the fact that today, as Decrop and Snelders (2004) note, going on holiday has become an integral part of many people's lives and, from a theoretical point of view, the amount of money or budget designated to it and the way it is spent are seen as an important part of the holiday decision-making process.

Hence, tourists' behaviour, specifically their expenditure patterns, is one of the most relevant variables to economic approaches. Through it, the economic impact of tourism activity can be studied. Tourists' expenditure affects many economic activities such as transportation, accommodation and restaurants. According to Lee and Chang (2008) and Craggs and Schofield (2009), tourism has long been viewed as a tool for economic development because of its ability to generate substantial economic benefits.

An increase in tourists' overall expenditure can be attributed to an increase 
in the total number of days tourists spend in a given destination, and/or to an increase in tourists' daily expenditure. Therefore, from a policy point of view, it is very important to understand what the main determinants of both daily expenditure and total number of overnight stays are. Analysis of the main determinants of overnight stays has to be done mainly at the macro level using time-series data to study how this figure has evolved over time and what the main factors driving its evolution are. In contrast, the main factors driving tourists' daily expenditure can be better analysed at the micro level, using a data set containing information on both tourists' and trip characteristics. In this paper, we address this second question using micro-data for peninsular and insular regions in the Spanish Mediterranean coast, during the years 2004 to 2009. Our data set is based on personal interviews at departure time and it is carried out by the SITS. This data set provides detailed information on expenditures, and tourists' and trip characteristics.

Most of the research on tourists' expenditure has focused on analysing total expenditure per tourist. Since this figure is the combination of stay length and daily expenditure, this type of analysis does not separate the main factors driving the trip duration from those determining the daily expenditure per tourist. In fact, the dynamics of these two variables, trip duration and daily expenditure, have been very different over the last decades. Stay length has decreased over time, as has been shown by Alegre and Pou (2006), Menezes et al (2008) and Artal et al (2010), and this decrease has been larger than the increase in daily expenditure that, on average and in real terms, has remained fairly stable, see Aguiló et al (2005).

This paper analyses the main factors driving tourists' daily expenditure. In particular, we focus on two aspects: how stay length influences daily expenditure and how the different activities tourists carry out during their stay affect tourists' expenditure. Assuming that agents have a budget to expend in tourism and in other goods, if stay length increases, daily spend may decrease. Regarding activities tourists can do when visiting the Spanish Mediterranean coast, besides the 'sun-and-sand' supply, they can also be interested in being enrolled in other activities such as playing golf, visiting museums, following health treatments, going to casinos, and so on. Activities carried out during the trip undoubtedly have an effect on the daily tourist expenditure and it is important to quantify this effect in order to design policies to increase tourism revenue in the countries of destination.

Certainly, to disentangle the effect of stay length and activities carried out by the tourist on his or her daily expenditure from the effect of other variables, we will have to include in our model other characteristics, both related to the trip and to the tourist, which undoubtedly also have an effect on tourists' expenditure. The regression model will be estimated by ordinary least square (OLS), and robust-to-heteroscedasticity standard errors will be calculated using pooled cross-section analysis.

Identification of the type of tourist having a higher economic impact on a mature destination like the Spanish Mediterranean coast will allow tourism policies to be shaped to attract the most interesting type of tourist and ensure their continued return to a given destination. Elasticity estimates drawn from this study should provide a basis for discussion of tourism-related policy issues and can be used as inputs for the economic policy models used by tourism policy 
analysts. In addition, some parameter estimates are of a particular relevance when developing marketing and promotional strategies. The objective should be, at least for mature destinations, to increase tourism revenue instead of the number of tourists (Urtasun and Gutierrez, 2006).

The rest of the contribution is organized as follows. The next section presents a literature review about tourism expenditure. The methodology follows with an econometric model and the results are then presented, while the main conclusions are presented at the end.

\section{Factors explaining tourists' expenditure}

According to Kozak et al (2008), there has been no consensus so far on how to define the term 'tourists' expenditure' as a dependent variable. Following these authors, we can classify literature depending on the definition of the dependent variable. First, there are studies based on calculating the average amount spent by tourists per trip (Leeworthy et al, 2001; Mok and Iverson, 2000; Mules, 1998). Second, there is an important amount of research that seeks to estimate expenditures per person but on a daily basis (Aguiló and Juaneda, 2000; Haukeland, 1996; Legoherel, 1998; Pol et al, 2006). Finally, there are studies that try to categorize tourists according to how much they spend in total (including companions and vacation days), which is used as a dependent variable in the model (Agarwal and Yochum, 1999; Jang et al, 2004; Kozak, 2001). The present study, as mentioned in the previous section, fits into the second type of research. Therefore, the dependent variable is daily tourists' expenditure.

Var and Lee (1990) show that methods used to analyse tourists' expenditure can be classified into three approaches: quantitative, qualitative and combined. 'Quantitative approaches, which are based on historical data, are further categorized into time series and causal methods. Causal methods include regression or econometric models and gravity or trip-generation models. Qualitative approaches that involve experts or group opinions include the Delphi and scenario-writing methods. Combined approaches either use weighting scheme techniques or combine quantitative and qualitative techniques together' (Lee $e t$ al, 1996, p 532). Our contribution in this study is included in the quantitative approach group using a causal method, since our econometric model explains which variables influence the daily tourists' expenditure. Nevertheless, among the relevant variables used to explain the daily tourists' expenditure, our investigation focuses on the role that stay length and activities carried out by tourists, besides enjoying sun and sand, have on daily expenditure.

The most widely used methodology to estimate expenditure equations is OLS. Aguiló and Juaneda (2000) analyse tourists' daily expenditure in the Balearic Islands using cross-section data. They analyse characteristics defining different tourist profiles according to expenditure levels. Their results highlight the most important factors influencing tourists' expenditure as: items paid in the home city, socio-economic status, nationality, age and their opinion on destination quality. Kozak et al (2008) estimate tourists' expenditure determinants in Turkey using self-generated survey data. They develop four models and they test the main determinants of tourists' expenditure. Their 
research findings suggest that expenditure changes are predicted by variations in variables such as country of residence, occupation, income, type of holiday, accommodation, travel companion, stay length, destination loyalty, package type, overall value for money and entertainment.

Jang et al (2004) also uses OLS on a sample of Japanese tourists going on holidays to the USA. They categorize tourists by income level and investigate travel expenditure determinants. They found that there are several sociodemographic and trip-related variables that contribute significantly to explain the variation in tourists' expenditure. These variables are age, occupation, travel companion, number of nights spent in the USA and repeated visits.

The effect of stay length on tourists' expenditure has been a recurrent topic in tourism research. Several studies have reported a positive association between stay length and total tourists' expenditure. This finding is unambiguous in the literature. The trip duration or stay length effect over daily tourists' expenditure is not so clear, however. Several contributions, such as Fredman (2008), Kim et al (2008), Laesser and Crouch (2006) or Mork and Iverson (2000), include stay length in expenditure regressions in a linear way, which implies that each additional day or night steadily increases total expenditure, as was noted in Thrane and Farstad (2011). Consistently, trip duration does not have any effect on daily expenditure in the above-mentioned studies. Conversely, Roehl and Fesenmaier (1995) find that the stay length increases trip expenditures per day while Aguiló and Juaneda (2000) report the opposite: a significant and negative effect of stay length.

In a recent study Alegre et al (2011) analyse how tourist motivations influence tourists' expenditure. They show that of tourists visiting Mallorca those seeking a typical sun-and-sand destination are less likely to be heavy spenders, whereas those coming mainly for cultural reasons, or for fun and social life, or for other tourist facilities are more likely to be heavy spenders. This result is in line with our findings that involvement in different activities (such as sports, cultural visits and so on) increases tourist expenditures.

Regarding the effect of some particular activities carried out by the tourist, some studies have analysed the effect on expenditure of performing one activity or another. Some examples of activities (and their consequences for expenditure) that have been analysed are: attendance at sports events in Daniels and Norman (2003), cultural visits in Taylor et al (1993) or De la Calle (2006), yacht charter tourism in Alcover et al (2011), gastronomic activities in Harrington and Ottenbacher (2010). Our contribution tries to analyse how tourists' daily expenditure is affected by the fact that, besides sun and sand, the tourist may demand other activities.

After reviewing the main approaches and methods used to analyse tourists' expenditure, we develop our empirical contribution in the remaining part of this study. We use a pool of data from a national survey conducted of foreign tourists who came to the Spanish Mediterranean regions. We have data for 6 years from 2004 to 2009 . We have estimated the model separately for each year and the estimated parameters were very similar for all years. This result indicates that the parameters of this model are stable and constant, at least during those 6 years. ${ }^{1}$ Therefore, we have pooled all data and included year dummies in the regression equation. We use two types of variables in our analyses: travel-related variables and socio-economic characteristics of the 
tourist to explain the real average daily expenditure. Our main focus, though, is on how stay length and activities enjoyed by tourists influence daily expenditure.

\section{Methodology}

The empirical part of this study has been carried out using the database 'Survey of Tourist Expense' known by the acronym EGATUR ('Encuesta de GAsto TURístico'). This survey is run by the SITS and provides monthly information about tourists' total expenditure made by non-residents during their trips to Spain. The surveyed population is foreign tourists and day-trippers who are nonresidents in Spain and enter the country either by road or by plane.

Our study is focused on foreign tourists during the years 2004 to 2009 whose main destination was one of the following regions: Balearic Islands, Catalonia, Valencia, Murcia and/or Andalusia. These five regions compose the Spanish Mediterranean coast and provide destinations for 'sun and sand' tourism. They receive more than two-thirds of total foreign tourists visiting Spain (Frontur, 2010).

The data set includes those tourists staying at least one night and no more than 30 consecutive nights. It represents $94 \%$ of the total completed surveys of tourists' expenditure (before data cleansing). The maximum level of 30 consecutive nights was set since foreigners staying for very long periods may have expenditure patterns closer to those of residents than to those of tourists (García et al, 2002).

Besides, we have not included in our expenditure any measure of the transportation cost of travelling to and returning from home to destination. The reason is the following: first, distance from origin to destination and transportation costs are highly positively correlated. Second, the transportation cost impact on daily expenditures diminishes with the stay length. Therefore, since the objective of our study is to analyse the main determinants of daily expenditures, if the transportation cost were included in our expenditure measure, our results could be skewed by these two effects.

Tourists coming to Spain on tourist packages (17.57\%) were removed from the database, since for this type of tourist it is difficult to disentangle the amount spent in transportation from home to destination from other expenses. Moreover, these tourists have previously paid a large part of the cost of the trip, and therefore their behaviour might be different from those not travelling on tourist packages. In this sense, the SITS (2010a) segments tourists who came on tourist packages and compares them with those who did not, obtaining significantly different results for each group. For instance, tourists coming on tourist packages have, on average, higher daily expenditures, although spending in the destination is much lower. Another difference is in the length of stay, which is, on average, shorter for tourists who come on tourist packages. Alegre and Pou (2008), Apostolakis and Jaffry (2009) and Anderson et al (2009) also analyse separately the expenses of the tourists who travel on packages.

Finally, the database has been deflated by the consumer price index (CPI), at constant 2006 euros, for each month. The CPI is provided by the Spanish 
National Statistics Institute, and includes expenditures in transportation, restaurants, housing, food and non-alcoholic beverages.

To sum up, the data used for this estimation consist of foreign tourists spending at least one and no more than 30 consecutive nights in Spain and not coming on a tourist package. Furthermore, expenditure excludes transportation costs to and from destinations and has been deflated by the CPI using 2006 as the base year. The total number of surveys used after this data cleansing is still quite high at 183,821 .

Using our database and the total number of foreign tourists visiting this part of Spain in the analysed period (see Frontur, 2010), we have estimated the economic impact of tourism in this area to be approximately $€ 5$ billion per year during the period 2004 to $2009 .^{2}$

According to our sample, the most common profile of a foreign tourist visiting this Spanish area is a person who has finished a university degree (53\%), comes by plane $(77 \%)$ for leisure reasons $(66 \%)$, with his or her family $(58 \%)$ in a group of two people $(51 \%)$ and has been to Spain before $(88 \%)$.

As is common in this type of survey, two-thirds of the people surveyed have declared medium income level. The second largest segment is the medium-high income group (22\% of the sample). As Table 1 shows, there is a remarkable difference in average daily expenditure among tourists with different income levels. For instance, high-income tourists spend on average €152 per day, whereas those declaring low income spend only $€ 61$ per day.

The average stay length for tourists in the Spanish Mediterranean coast is a little more than a week ( 7.42 nights). If we divide tourists into four groups depending on the trip duration (less than 4 nights, from 4-7, from 8-14 and more than 14), the largest proportion, $41.5 \%$, is those staying between 4 days and 1 week and the smallest, $11 \%$, is those staying more than 2 weeks. Regarding expenditures, we can see in Table 1 that the longer the stay length the lower the daily expenditure. The reason for this result is twofold. First, tourists staying for long periods are less likely to use hotels than those staying for short periods and, since hotels are more expensive than second homes or rented flats, this partially explains differences in average expenditures depending on the trip duration. Second, it is likely that long stays have some scale economies not present in short visits. We will be able to disentangle these two effects in the multivariate regression presented in the section

Table 1. Daily expenditure (euros) by income group and length of stay.

\begin{tabular}{lrrrcr}
\hline Income/stay length (nights) & $1-3$ & $4-7$ & $8-14$ & More than 14 & All \\
& & & & & 71.76 \\
High & 240.70 & 151.72 & 93.82 & 62.19 & 151.93 \\
Medium-high & 185.22 & 115.43 & 85.90 & 45.52 & 92.86 \\
Medium-medium & 151.37 & 83.15 & 62.79 & 37.46 & 67.79 \\
Medium-low & 98.20 & 64.86 & 51.63 & 34.07 & 60.58 \\
Low & 92.87 & 58.45 & 45.75 & 51.91 & 100.91 \\
All & 162.30 & 90.89 & 69.44 & & \\
\hline
\end{tabular}


Table 2. Daily expenditure (euros) by type of accommodation and activity.

\begin{tabular}{|c|c|c|c|c|c|}
\hline Activity & $\begin{array}{c}\text { Activity } \\
\text { undertaken }\end{array}$ & $\begin{array}{l}\text { Hotel } \\
\text { and } \\
\text { similar }\end{array}$ & $\begin{array}{c}\text { Rented } \\
\text { apartments }\end{array}$ & $\begin{array}{c}\text { Second } \\
\text { homes or } \\
\text { with friends/ } \\
\text { family }\end{array}$ & All \\
\hline \multirow[t]{2}{*}{ Golf } & Yes & 157.65 & 81.48 & 74.11 & 95.72 \\
\hline & No & 147.28 & 77.22 & 53.48 & 101.02 \\
\hline \multirow[t]{2}{*}{ Cultural visits } & Yes & 130.29 & 75.98 & 53.86 & 95.89 \\
\hline & No & 166.58 & 78.99 & 54.38 & 105.69 \\
\hline \multirow[t]{2}{*}{ Cultural events } & Yes & 153.51 & 91.71 & 61.81 & 109.09 \\
\hline & No & 146.90 & 76.11 & 53.56 & 100.25 \\
\hline \multirow[t]{2}{*}{ Theme park visits } & Yes & 120.06 & 69.39 & 49.24 & 85.45 \\
\hline & No & 148.72 & 78.07 & 54.36 & 101.69 \\
\hline \multirow{2}{*}{ Gastronomic activities } & Yes & 185.36 & 97.92 & 67.60 & 120.36 \\
\hline & No & 143.68 & 75.38 & 52.40 & 98.75 \\
\hline \multirow[t]{2}{*}{ Discotheques/clubs } & Yes & 141.28 & 88.60 & 59.15 & 97.79 \\
\hline & No & 148.77 & 74.72 & 52.72 & 101.69 \\
\hline \multirow[t]{2}{*}{ Health treatments } & Yes & 166.23 & 79.87 & 60.65 & 117.96 \\
\hline & No & 146.94 & 77.25 & 54.03 & 100.54 \\
\hline \multirow[t]{2}{*}{ Sailing } & Yes & 161.72 & 90.67 & 71.20 & 94.43 \\
\hline & $\mathrm{No}$ & 147.35 & 77.01 & 53.99 & 100.96 \\
\hline \multirow[t]{2}{*}{ Adventure sports } & Yes & 183.62 & 84.96 & 54.95 & 106.18 \\
\hline & No & 147.31 & 77.22 & 54.16 & 100.89 \\
\hline \multirow[t]{2}{*}{ Sport events } & Yes & 173.52 & 95.50 & 67.72 & 124.85 \\
\hline & No & 146.86 & 76.97 & 53.93 & 100.45 \\
\hline \multirow[t]{2}{*}{ Casinos } & Yes & 193.11 & 115.53 & 72.53 & 135.39 \\
\hline & No & 146.67 & 76.78 & 53.88 & 100.37 \\
\hline All & & 147.40 & 77.30 & 54.16 & 100.91 \\
\hline
\end{tabular}

entitled 'Variables and the model'. It is worth emphasizing that those differences cannot be due to the lower transportation cost, since our expenditure measure only includes the daily expenditure during the trip and not the transportation cost to and from Spain.

The type of accommodation used by the majority of foreign tourists during their trips to this Spanish area is a hotel or similar (45\%), although the proportion staying in second homes (owned properties or with family/friends) is also very large (39\%). As we can see in Table 2, there is an important difference in daily expenditure between both types of tourists (€147/day in the case of accommodation in hotels, including the accommodation cost, and only $€ 54 /$ day in the case of second homes).

Finally, our data set contains information on different activities carried out by tourists during their visit. It is important to know whether there are differences in how much tourists spend depending on the activities undertaken during their visit. In Table 2 we present, for several activities, the average daily expenditure for the group of tourists who carried out that activity and for the group who did not. From the last column of this table, it seems that for some activities, such as playing golf, undertaking the activity decreases expenditures. 
However, tourists differ in several dimensions, and it might well happen that tourists conducting certain activities are more likely to have certain characteristics that may explain low expenditures. This is clearly the case of playing golf when we take into account the type of accommodation. Tourists going to hotels are less likely to play golf than those using a second home. Then, since tourists going to hotels spend more it may appear that playing golf decreases expenditures. However, when the type of accommodation is taken into account, that is, when we compare tourists using the same type of accommodation, it is clear that those playing golf spend more on average.

Regarding other activities, such as cultural and theme park visits, and even adjusting for type of accommodation, we find that tourists who carried out that activity spend less on average than those who did not. This result does not necessarily imply that experiencing cultural visits or visiting theme parks decreases tourist expenditure. It might well happen that there are some other characteristics we have not taken into account to explain this result. We will be able to quantify the true effect of all activities on tourist daily expenditure on the basis of the multivariate regression analysis performed in the section, 'Study results and discussion'.

\section{Variables and the model}

As we have already mentioned, the purpose of this study is to quantify the main determinants of foreign tourist daily expenditure, and in particular how stay length and the different activities performed by tourists during their visit to Spain influence their expenditure patterns. The dependent variable of the model is $\log$ daily expenditure, where expenditure includes accommodation, transportation cost in destination, restaurants, car rental, shopping, gifts and other expenditures. As we mentioned above, our expenditure measure does not include the transportation cost from the country of residence to Spain and return. Expenditure is deflated using the CPI.

Explanatory variables include several dummy variables to reflect whether the tourist performed different activities during his or her stay. We also control for several socio-economic tourist characteristics, such as age, education level and income level; and several trip characteristics, such as type of transportation, type of accommodation, group size, relationship with other group members, main reason for the trip, previous visits and trip duration. Finally, we include year dummies to account for variation in the business cycle, month dummies to account for seasonal effects and regional dummies.

The proposed regression model is:

$$
\operatorname{Ln} Y=\beta_{0}+\beta^{\prime} X+\varepsilon,
$$

where $Y$ is the real daily expenditure, $\beta_{0}$ is the constant term, $X$ includes all explanatory variables used in the estimation and $\mathrm{e}$ is the error term. Most variables are sets of dummies; however, we also have some variables in our model that are not binary, such us stay length. Therefore, the model intercept does not have the interpretation of being the average of the dependent variable for the tourist of reference, as in some other studies.

We will now describe all explanatory variables used in the model. 


\section{Activities}

For each activity, we consider a dummy variable that takes the value 1 if the tourist has performed the activity and 0 otherwise. The activities considered are:

- playing golf;

- cultural visits;

- cultural events;

- theme parks;

- gastronomic activities;

- discotheques;

- health treatments;

- sailing;

- adventure sports;

- sport events;

- casinos.

\section{Socio-economic characteristics}

We consider several sets of dummy variable reflecting some socio-economic tourist characteristics. These sets of dummies are (the omitted reference category is written within square parentheses):

- age: 0-24, 25-44, [45-64], over 65;

- educational level: [less than high school], high school, university degree;

- income level: [low], medium-low, medium-medium, medium-high, high. ${ }^{3}$

Income categories are subjective and they may well reflect the relative income level in the tourist's country. Let us consider, for instance, two tourists reporting the same income level. Tourist $k$ is from a rich country and tourist $j$ from a relatively poor country. Then, it is quite likely that the income level of tourist $k$ is higher than the income level of tourist $j$. To try to correct income subjectivity, we have also included in our regression the log of the annual GDP per capita of the tourist's country of origin in constant 2006 euros.

Another issue that might influence expenditure patterns is differences in price levels across countries. To control this, we also include the log of the purchasing power parity (PPP) of the tourist's country of origin relative to the Spanish PPP. The effect of this variable on tourist expenditure is not clear $a$ priori. On the one hand, the fact that some countries have higher prices than others implies that tourists coming from expensive countries have to spend more in their country on goods like food, housing, etc and, therefore, they will have less money to spend in tourism when arriving in Spain. This effect will imply that the origin-country PPP has a negative effect on expenditures. On the other hand, tourists coming from expensive countries might buy some goods in Spain where they are cheaper, like clothing, instead of buying them in their own country. This second effect will imply that the PPP has a positive effect on expenditures. Which of the two effects prevails is an empirical issue.

The socio-economic characteristics of the tourists could be highly collinear. The reasons are twofold. First, there could be a strong correlation between the 
study level and the income level since more educated people tend to have higher earnings. Income and age could also be strongly correlated since income increases over the life-cycle, at least until retirement. Second, since the data are collected by personal interview, tourists may 'adjust' their answers. For example, tourists with a university degree may report high income, even if their income is not high, since they may think that this is the social norm and they are ashamed of declaring low income when they have reported having a university degree. To check whether the socio-economic characteristics are highly correlated we have calculated the Cramér's V statistic between income and study levels and between income and age groups. We find that the Cramér's V statistic between income and study level is 0.1501 and between income and age is 0.2162 . These values are rather low and they indicate that these variables are not highly collinear.

\section{Characteristics of the trip}

We consider several sets of dummy variable reflecting some characteristics of the trip. These sets of dummies are (the omitted category is written within square brackets):

- type of accommodation: [hotel], second residence (own property or yielded by relatives or friends), rented, other (camping, apartments, etc);

- main reason for the trip: [leisure], business, personal;

- relationship with other group members: [family], friends;

- group size: one, two, three, [more than three];

- first visit to Spain: [yes], no;

- means of transport used to the destination: [road or train], plane.

We also control for the trip duration by including the number of days the tourist spends in Spain and its square. By including the square, we are allowing the stay length effect on daily expenditure to be non-linear.

\section{Other controls}

- Regional dummies: [Andalusia], Valencia, Murcia, Catalonia, Balearic Islands.

- Month dummies: January, February, March, April, May, June, July, August, September, [November], December.

- Year dummies: [2004], 2005, 2006, 2007, 2008.

\section{Study results and discussion}

The model in Equation (1) has been estimated by OLS with robust-toheteroscedasticity standard errors since the White-heteroscedasticity test strongly rejects the null hypothesis of homoscedastic errors. These results are presented in Table 3. We will now discuss the main results. First, we analyse the effect on daily expenditures of activities performed by tourists. Second, we comment on the influence of trip characteristics and finally, we discuss the effect of tourist characteristics. 
Table 3. Results of the OLS regression.

Explanatory variables

(reference category in parentheses)

OLS robust-to-heteroscedasticity

\section{Activities}

Golf

Cultural visits

Cultural events

Theme parks visits

Gastronomic activities

Discotheques/clubs

Health treatments

Sailing

Adventure sports

Sport events

Casinos

Stay length

Stay length ${ }^{2}$

$\begin{array}{rrr}0.2174^{* * *} & (0.0097) \\ 0.0761^{* * * *} & (0.0029) \\ 0.1569^{* * *} & (0.0053) \\ 0.0447^{* * *} & (0.0061) \\ 0.1868^{* * *} & (0.0048) \\ 0.1001^{* * *} & (0.0037) \\ 0.0904^{* * *} & (0.0093) \\ 0.0490^{* * *} & (0.0166) \\ 0.1115^{* * *} & (0.0272) \\ 0.1656^{* * *} & (0.0104) \\ 0.1929^{* * * *} & (0.0119) \\ -0.0659^{* * *} & (0.0009) \\ 0.0013^{* * *} & (0.0000)\end{array}$

Accommodation (hotel)

Property

Rent

$-0.7854^{* * *}$

(0.0039)

Others

$-0.2868^{* * * *}$

$(0.0054)$

$-0.3697^{* * *}$

(0.0071)

Reason for trip (leisure)

Business

$0.2678^{* * *}$

$(0.0053)$

Personal

$-0.0866^{* * *}$

$(0.0045)$

Travel companion (family)

Friends

Group size (four)

One

$\begin{array}{ll}0.4455^{\text {*** }} & (0.0064) \\ 0.1733^{* * *} & (0.0054) \\ 0.0294^{* * *} & (0.0067)\end{array}$

Three

\begin{tabular}{|c|c|}
\hline $0.0625^{* * * *}$ & $(0.0133)$ \\
\hline $0.1661^{* * * *}$ & $(0.0120$ \\
\hline $0.3289^{* * * *}$ & (0.012 \\
\hline $0.4956^{* * *}$ & $(0.013$ \\
\hline $0.1816^{* * * *}$ & $(0.009$ \\
\hline $0.0462^{* * * *}$ & $(0.019$ \\
\hline
\end{tabular}

Income level (low)

Medium-low

Medium-medium

Medium-high

High

$\ln ($ GDP $)$

$\ln (\mathrm{PPP})$

$\begin{array}{ll}-0.2285^{* * *} & (0.0061) \\ -0.0783^{* * *} & (0.0032) \\ -0.0653^{* * *} & (0.0053)\end{array}$

Age (45-64)

0-24

25-44

Over 65

$$
\begin{array}{ll}
0.0379^{* * *} & (0.0056) \\
0.1254^{* * *} & (0.0057)
\end{array}
$$

Means of transport used to destination (land)

Air 
Table 3 continued.

Explanatory variables

OLS robust-to-heteroscedasticity

(reference category in parentheses)

Past visits (first time)

More times

$-0.0244^{* * *}$

$(0.0042)$

$R^{2}$ adjusted

0.5477

White's Heteroscedasticity test ( $p$-value in parentheses) $\quad 14395.9$

(0.0000)

Notes: OLS estimates: standard errors robust-to-heteroscedasticity (in parentheses). Dependent variable: $\log$ daily real expenditure. The regression includes regional dummies, year dummies and month dummies. ${ }^{* * *}$ Significant at $1 \%(p \leq 0.01) ;{ }^{* *}$ significant at $5 \%(p \leq 0.05) ;{ }^{*}$ significant at $10 \%$ $(p \leq 0.1)$.

Source: Authors' calculations using data from the data base EGATUR run by the Spanish Institute for Tourism Studies.

\section{Activities}

Contrary to what Table 2 suggests, once we control for tourist and trip characteristics, all activities contribute to increase daily expenditures. Playing golf and going to the casino are the two activities with a stronger effect in daily expenditures. Playing golf increases daily expenditures by $22 \%$, while the effect of going to the casino is $19 \%$. This shows that it is necessary and advisable to develop and implement some strategies or policies to complement the offer of 'sun and sand' with an offer of activities or experiences to increase tourist expenditure.

\section{Variables related to the trip}

Length of stay

We have included in our regression the number of nights the tourist stays in Spain and its square to allow a potential non-linear effect of the trip duration on daily expenditures. Looking at the results, we can say that the effect is clearly non-linear since both the number of nights and its square are highly significant. The trip duration has a negative effect on daily expenditures, but this effect is smaller the longer the trip. For instance, increasing the trip duration from one to two days decreases daily expenditures by $6.33 \%$, whereas increasing the duration from 14 to 15 days decreases daily expenditures only by $2.95 \%$. This result is in line with the result obtained by Aguiló and Juaneda (2000), which also allows a potential non-linearity in the trip duration effect on daily expenditures.

\section{Type of accommodation}

The accommodation cost is a very important part of the trip cost. Since hotels are in general more expensive than rented flats or owned homes, it is not surprising that the type of accommodation has a strong impact on daily expenditures. According to our results, a person staying in a second home (own accommodation or with family or friends), spends about $79 \%$ less in daily expenditure than a tourist staying in a hotel or similar. Since the estimated 
difference is so large, it is unlikely that it is only due to the difference in the accommodation cost, but it probably also comes from differences in expenditures in other items, like, for instance, eating at restaurants versus eating at home.

\section{Main reason for the trip}

The main reason for the trip has also a strong influence in tourist expenditures. Tourists coming for business spend 27\% more than those coming mainly for leisure. This result is in line with Suh and McAvoy (2005), who analyse tourist preferences and expenditures.

\section{Travel companion}

A tourist travelling with friends spends $21 \%$ more than a person travelling with his or her family. Downward (2003) and Jang et al (2004) found similar results. In contrast, Craggs and Schofield (2009) show that people coming with their families are medium to heavy spenders, while those coming with work colleagues tend to be light spenders.

\section{Group size}

The group size has an important effect on daily expenditures. Travelling alone increases the expenditure per capita by $45 \%$ compared to the reference group of four people. When the group size is two or three, the average expenditure per day is $17 \%$ or $3 \%$ larger, respectively. Therefore, our results suggest that there are scale economies in the group size, since groups can share some expenditures and, therefore, incur lower expenditure per capita compared to those travelling alone. Mok and Iverson (2000) also found that daily expenses per person decrease as the number of companions rose.

\section{First visit}

The fact that this is not the first time in Spain decreases daily expenditures by $2.5 \%$. This result is line with Alegre and Cladera (2010) who find that repeat visitors to Mallorca spend less than first-timers.

\section{Tourist characteristics}

\section{Income level}

Since we do not observe tourist income, but the income group to which he or she belongs, we cannot estimate the income elasticity and, therefore, we cannot test whether tourism is a normal good. However, we find that richer tourists spend more on average than poor ones. In particular, high-income tourists spend $50 \%$ more than low-income visitors, whereas this difference is only $17 \%$ when we compare middle- and low-income tourists. This result is in accordance with literature and it has already been found by Lee et al (1996), Jang et al (2004), Fish and Waggle (1996), Agarwal and Yochum (1999) and Davies and Mangan (1992), among others.

As we have already mentioned, we have tried to correct subjectivity of our income measure by including in our regression the logarithm of the GDP per 
capita of the country of origin. The effect of this variable on tourist daily expenditure is positive and highly significant as was expected. This result indicates that tourists declaring to be in the same income group have on average higher income the richer the country of origin is.

We have also included in our regression the logarithm of the PPP of the tourist country related to the Spanish PPP to control for differences in prices across countries. The effect of this variable is positive but relatively small. This result indicates that the prevailing price effect is that tourists coming from expensive countries buy some goods in Spain instead of buying them in their own country, although the price effect is not very large. This result is in line with Vietze (2012) who found that relative low prices in the country of origin discourage people from travelling to the USA.

Age

Our results suggest that there is an inverted U-shape relationship between tourist age and his or her daily expenditure. Young and old tourists spend less on average than the middle aged. The reference group, that is tourists between 44 and 65 years of age, spend more on average than tourists in any other age group. The young spend the least: $23 \%$ less than those in the reference group. Our result could arise from differences in preferences over the life-cycle or to liquidity constraints. We cannot separate these two hypotheses since we do not have data on tourist total expenditure. Our results are in line with Craggs and Schofield (2009).

\section{Study level}

Highly educated tourists spend more than those with a low level of education. In particular, tourists with a university degree spend on average $12.5 \%$ more than tourists who have only completed compulsory education.

\section{Conclusion}

This study has examined the determinants of foreign tourist expenditure by defining the dependent variable as the 'real daily expense per person'. The empirical part used a pooled cross-section OLS analysis and robust-toheteroscedasticity standard errors on data for the regions in the Spanish Mediterranean coast. The main advantage of such a model is that it allows for estimation of the expense profile of tourists with different characteristics. Furthermore, such a model allows testing of whether there are significant differences in the expenditure level among tourists with different profiles. The micro-econometric approach has allowed us to quantify existing differences among expenditure tourist patterns, accounting in that way for the inherent heterogeneity of the data in the estimation process.

One of the main purposes of this study was to quantify how alternative activities offered to the tourist to complement a sun and sand destination influence tourist daily expenditures. Our results suggest that such activities have substantially contributed to increased tourist daily expenditures. This result is very relevant, since it confirms the importance of the complementary 
sun-and-sand supply that a consolidated product, such as the Spanish Mediterranean coast, should offer to tourists. Consistently, having a complementary offer to sun-and-sand helps to increase the daily expenditures of tourists visiting the Mediterranean coast.

The activities that increase, to a large extent, tourist daily expenditures are playing golf, going to the casino, attending sports events and gastronomic activities. Conversely, visiting theme parks, watersports and undertaking cultural visits, although increasing daily expenditures, have a smaller impact than the previous examples. This result is very relevant for managers of mature tourism destinations, such as the Spanish Mediterranean coast, who want to complement the sun-and-sand offer with other complementary offers like those analysed in this study.

The other main purpose of this analysis was to study how the trip duration affects tourist daily expenditures. We have found that the trip duration has a negative impact on daily expenditures although this impact decreases as the trip duration becomes longer. For instance, increasing the trip duration from 1 to 2 days decreases daily expenditures by $6.33 \%$ whereas increasing the duration from 14 to 15 days decreases daily expenditures only by $2.95 \%$. That is, longer trips are associated with smaller daily expenditures although the reduction decreases as stay length increases. It is likely that the tourist has a budget for tourism purposes and therefore he or she is forced to curb expenditures as the stay is prolonged.

These findings provide important information for those marketing destinations in the five regions considered. As mentioned by Jang et al (2004) travel expenditure patterns are vital to travel organizers and destination marketers. A tourist policy compatible with sustainable tourism should consider tourist daily expenditure, as a marketing aim, rather than trying to achieve the largest possible number of tourists.

These results also confirm that socio-economic and trip characteristics are important factors driving tourist expenditure choices. The tourist socioeconomic feature affecting the daily expenditure to a greater degree is income level; in fact, tourists declaring a high income spend on average $50 \%$ more than those declaring low income.

The variable related to the trip explaining the biggest differences in personal, real daily expenditure is the type of accommodation chosen by the tourist. Tourists staying in a second home spend $79 \%$ less each day than those staying in hotels. This result is quite relevant because accommodation in a second home has become the option preferred by a large proportion of tourists visiting this Spanish area.

Other relevant trip characteristics are the main reason for the trip, tourist group size and travel companions, which also play a substantial role in explaining daily expenditure. It is found that there is an increasing return to scale as the number of people in the group of tourists grows.

The daily tourist expenditure in a destination like the Spanish Mediterranean coast will increase if tourists can do other activities apart from visit the beach, they stay at hotels, they come in groups of friends with a limited size and their stays are not very long. In contrast, promoting only family beach tourism, staying at second residences and over a longer period of time will reduce the daily expenditure of foreign tourists. 


\section{Endnotes}

1. These results are available from the authors on request.

2. This figure is computed as the average number of nights, times average daily expenditure, times number of tourists visiting this part of Spain from 2004 to 2009.

3. The tourist auto classified in this scale.

\section{References}

Agarwal, V.B., and Yochum, G.R. (1999), 'Tourist spending and race of visitors', Journal of Travel Research, Vol 38, No 2, pp 173-176.

Aguiló, E., and Juaneda, C. (2000), 'Tourist expenditure for mass tourism markets', Annals of Tourism Research, Vol 27, No 3, pp 624-637.

Aguiló, E., Alegre, J., and Sard, M. (2005), 'The persistence of the sun and sand tourism model', Tourism Management, Vol 26, pp 219-231.

Alcover, A., Alemany, M., Jacob, M., Payeras, M., García, A., Martínez-Ribes, L. (2011), 'The economic impact of yacht charter tourism on the Balearic economy', Tourism Economics, Vol 17, No 3, pp 625-638.

Alegre, J., and Cladera, M. (2010), 'Tourist expenditure and quality: why repeat tourists can spend less than first-timers', Tourism Economics, Vol 16, No 3, pp 517-533.

Alegre, J., and Pou, L. (2006), 'The length of stay in the demand for tourism', Tourist Management, Vol 27, pp 1343-1355.

Alegre, J., and Pou, L. (2008), 'Tourism expenditure and all-inclusive packages - the case of a mature Mediterranean destination', Tourism Economics, Vol 14, No 3, pp 645-655.

Alegre, J., Cladera, M., and Sard, M. (2011), 'Analysing the influence of tourist motivations on tourist expenditure at a sun-and-sand destination', Tourism Economics, Vol 17, No 4, pp 813-832.

Anderson, W., Juaneda, C., and Sastre, F. (2009), 'Influences of pro-all-inclusive travel decisions', Tourism Review, Vol 64, No 2, pp 4-18.

Apostolakis, A., and Jaffry, S. (2009), 'Examining expenditure patterns of British tourists to Greece', International Journal of Tourism Policy, Vol 2, No 3, pp 187-205.

Artal Tur, A., García-Sánchez, A., and Navarro Azorín, J.M. (2010), 'Factores determinantes de la duración de la estancia turística en el destino de sol y playa: el caso de la Región de Murcia', Cuadernos de Economía, Vol 33, No 91, pp 43-67.

Craggs, R., and Schofield, P. (2009), 'Expenditure-based segmentation and visitor profiling: regeneration the Quays in Salford, UK', Tourism Economics, Vol 15, No 1, pp 243-269.

Daniels, M.J., and Norman, W.C. (2003), 'Estimating the economic impacts of seven regular sport tourism events', Journal of Sport \& Tourism, Vol 8, No 4, pp 214-222.

Davies, B., and Mangan, J. (1992), 'Family expenditure on hotels and holidays', Journal of Tourism Research, 19, pp 691-699.

De la Calle, M. (2006), La ciudad histórica como destino turístico, 2nd edn, Colección Ariel Historia, Editorial Ariel, Barcelona.

Decrop, A., and Snelders, D. (2004), 'Planning the summer vacation. An adaptable process', Annals of Tourism Research, Vol 31, No 4, pp 1008-1030.

Downward, P. (2003), 'Beyond the demand for day-visits: an analysis of visitor spending', Tourism Economics, Vol 9, No 1, pp 67-76.

Fredman, P. (2008), 'Determinants of visitor expenditures in mountain tourism', Tourism Economics, Vol 14, No 2, pp 297-311.

Fish, M., and Waggle, D. (1996), 'Current income versus total expenditure measures in regression models of vacation and pleasure travel', Journal of Travel Research, Vol 35, No 2, pp 70-74.

García, A., Artal, A., and Ramos, J.M. (2002), 'El turismo del Mar Menor: predominio de la segunda residencia', Cuadernos de Turismo, Vol 9, pp 33-45.

Haukeland, J.V. (1996), 'Norwegian and foreign tourists' expenditures in Norway during the summer of 1995', The Tourist Review, Vol 3, pp 45-54.

Harrington, R.J., and Ottenbacher, M.C. (2010), 'Culinary tourism - a case study of the gastronomic capital', Journal of Culinary Science and Technology, Vol 8, No 1, pp 14-32.

Jang, S., Bai, B., Hong, G.S., and O'Leary, J.T. (2004), 'Understanding travel expenditure patterns: a study of Japanese pleasure travellers to the United States by income level', Tourism Management, Vol 25, No 3, pp 331-341. 
Kim, S.S., Han, H., and Chon, K. (2008), 'Estimation of the determinants of expenditure by festival visitors', Tourism Analysis, Vol 13, No 4, pp 387-401.

Kozak, M. (2001), 'An analysis of tourist spending and its determinants', An International Journal of Hospitality and Tourism Research, Vol 12, No 2, pp 196-202.

Kozak, M., Gokovali, U., and Bahar, O. (2008), 'Estimating the determinants of tourist spending: a comparison of four models', Tourism Analysis, Vol 13, No 2, pp 143-155.

Laesser, C., and Crouch, G.I. (2006), 'Segmenting markets by travel expenditure patterns: the case of international visitors to Australia', Journal of Travel Research, Vol 44, No 4, pp 397-406.

Leeworthy, V.R., Wiley, P., English, D., and Kriesel, W. (2001), 'Correcting response bias in tourist spending surveys', Annals of Tourism Research, Vol 28, pp 83-97.

Legoherel, P. (1998), 'Toward a market segmentation of the tourism trade: expenditure levels and consumer behavior instability', Journal of Travel and Tourism Marketing, Vol 7, No 3, pp 19-39.

Lee, C., Var, T., and Blaine, T.W. (1996), 'Determinants of inbound tourist expenditures', Annals of Tourism Research, Vol 23, No 3, pp 527-542.

Lee, Ch., and Chang, Ch. (2008), 'Tourism development and economic growth-a nonlinear approach', Tourism Management, Vol 29, No 1, pp 180-192.

Menezes, A., Moniz, A., and Vieira, J. (2008), 'The determinants of length of stay of tourists in the Azores', Tourism Economics, Vol 14, pp 1-18.

Mok, C., and Iverson, T.J. (2000), 'Expenditure-based segmentation: Taiwanese tourists to Guam', Tourism Management, Vol 21, No 3, pp 299-305.

Mules, T. (1998), 'Decomposition of Australian tourist expenditure', Tourism Management, Vol 19, No 3, pp 267-271.

Pol, A. P., Pascual, M.B., and Vázquez, P.C. (2006), 'Robust estimators and bootstrap confidence intervals applied to tourism spending', Tourism Management, Vol 27, No 1, pp 42-50.

Roehl, W.S., and Fesenmaier, D.R. (1995), 'Modelling the influence of information obtained at state welcome centers on visitor expenditures', Journal of Travel and Tourism Marketing, Vol 4, No 3, pp 19-28.

Spanish Institute for Tourism Studies (2010), 'Encuesta de Movimientos Turísticos en Frontera (FRONTUR). Annual report' (http://www.iet.tourspain.es/es-es/estadisticas/frontur/paginas/ default.aspx, accessed 9 May 2013).

Suh, Y.K., and McAvoy, L. (2005), 'Preferences and trip expenditure: a conjoint analysis of visitors to Seoul, Korea', Tourism Management, Vol 26, No 3, pp 325-333.

Taylor, D.T., Fletcher, R.R., and Clabaugh, T. (1993), 'A comparison of characteristics, regional expenditures and economic impact of visitors to historical sites with other recreational visitors', Journal of Travel Research, Vol 32, No 5, pp 30-35.

Thrane, C., and Farstad, E. (2011), 'Domestic tourism expenditures: the non-linear effects of length of stay and travel party size', Tourism Management, Vol 32, pp 46-52.

Urtasun, A., and Gutierrez, I. (2006), 'Tourism agglomeration and its impact on social welfare: an empirical approach to the Spanish case', Tourism Management, Vol 27, pp 901-912.

Var, T., and Lee, C.H. (1990), 'Tourism forecasting: state-of-the-art techniques from proceedings of 1990', Outdoor Recreation Trends Symposium III, March, 1990, Indiana University, Indianapolis.

Vietze, C. (2012), 'Cultural effects on inbound tourism into the USA: a gravity approach', Tourism Economics, Vol 18, no 1, pp 121-138.

World Tourism Organization (2010), 'Tourism highlights. 2010 edition' (www.unwto.org).

WTTC (2005), Annual Reports, Progress and Priorities 2004/05, The World Travel and Tourism Council.

Zhao, W., and Ritchie, B. (2007), 'An investigation of academic leadership in tourism research: 1985-2004', Tourism Management, Vol 28, pp 476-490. 